\title{
Silicon Carbide Micro-devices for Combustion Gas Sensing under Harsh Conditions
}

Semi-annual Technical Report

Reporting Period:

October 1, 2003 to March 31, 2004

Ruby N. Ghosh ${ }^{1}$, Peter Tobias ${ }^{1}$ and Roger G. Tobin ${ }^{2}$

April 2004

DOE Award Number: DE-FC26-03NT41847

${ }^{1}$ Center for Sensor Materials and Dept. of Physics \& Astronomy

2167 Biomedical Physical Sciences Building

Michigan State University

${ }^{2}$ Dept. of Physics and Astronomy

4 Colby St.

Tufts University 


\section{DISCLAIMER}

"This report was prepared as an account of work sponsored by an agency of the United States Government. Neither the United States Government nor any agency thereof, nor any of their employees, makes warranty, express or implied, or assumes any legal liability or responsibility for the accuracy, completeness, or usefulness of any information, apparatus, product, or process disclosed, or represents that its use would not infringe privately owned rights. Reference herein to any specific commercial product, process, or service by trade name, trademark, manufacturer, or otherwise does not necessarily constitute or imply its endorsement, recommendation, or favoring by the United States Government or any agency thereof. The views and opinions of the authors expressed herein do not necessarily state or reflect those of the United States Government or any agency thereof."

\footnotetext{
$\underline{\text { ABSTRACT }}$

A sensor based on the wide bandgap semiconductor, silicon carbide ( $\mathrm{SiC}$ ), has been developed for the detection of combustion products in power plant environments. The sensor is a catalytic gate field effect device that can detect hydrogen containing species in chemically reactive, high temperature environments. Robust metallization and electrical contacting techniques have been developed for device operation at elevated temperatures. To characterize the time response of the sensor responses in the millisecond range, a conceptually new apparatus has been built. Software has been developed to cope with the requirements of fast sensor control and data recording. In addition user friendly software has been developed to facilitate use of the SiC sensors for industrial process control applications.
} 


\section{TABLE OF CONTENTS}

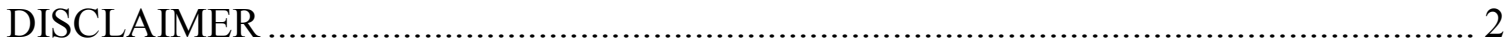

ABSTRACT .

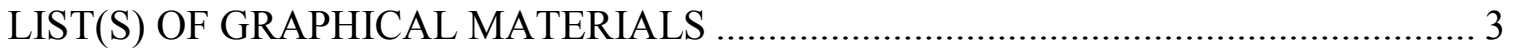

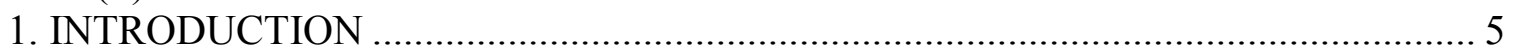

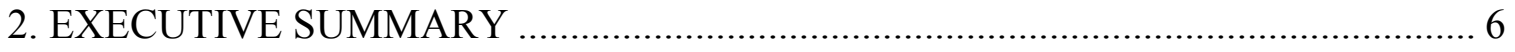

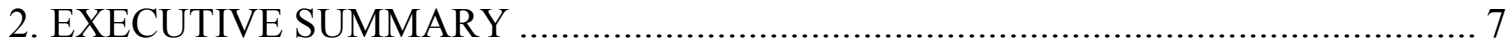

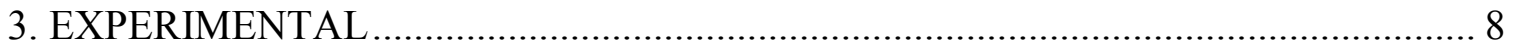

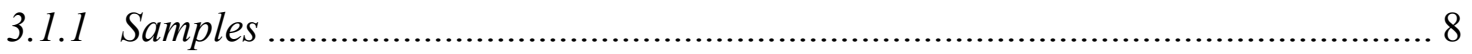

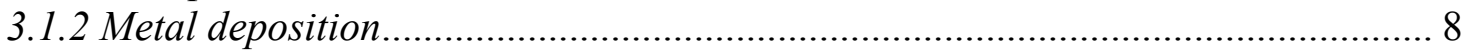

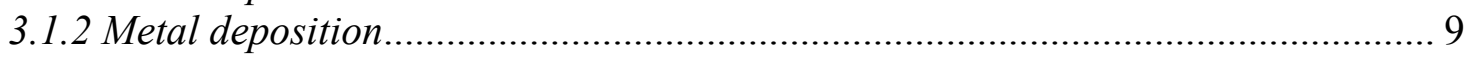

3.1.3 Contact to the metal gates................................................................................. 9

3.1.4 X-ray diffraction measurements ........................................................................ 9

3.2 Time Resolved Fast Sensor Test Assembly …………...................................... 10

3.2.1 Program for sensor control and data acquisition............................................ 10

3.2.2 Time resolved data acquisition program ............................................................ 11

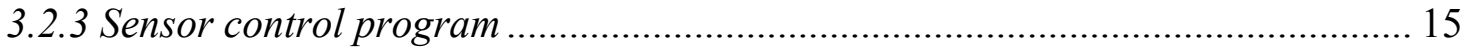

3.2.4 Fast automated control and data acquisition ..................................................... 16

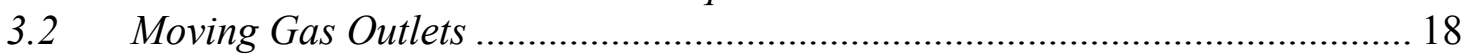

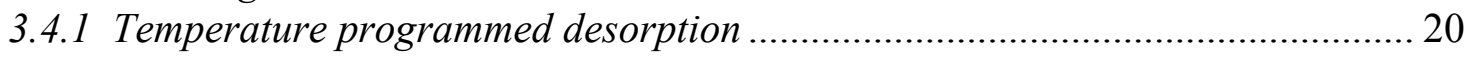

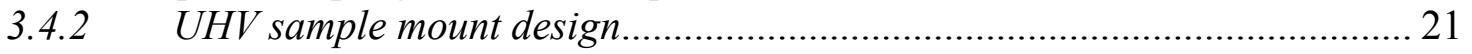

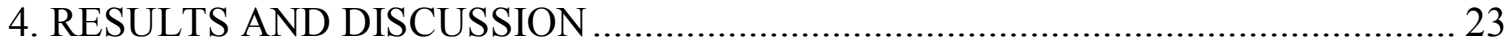

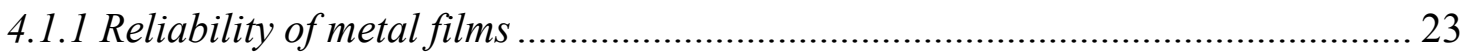

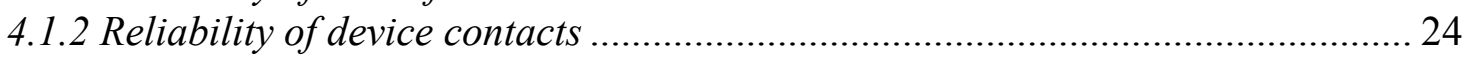

4.2 Time Resolved Fast Sensor Test Assembly …………………………………... 24

4.2.1 Program for sensor control and data acquisition............................................. 25

4.2.2 Time resolved data acquisition program ……….............................................. 25

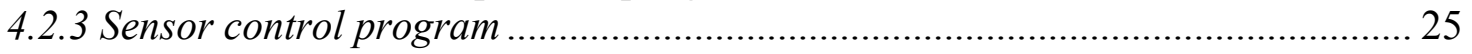

4.2.4 Fast automated control and data acquisition .................................................... 25

4.3 Moving Gas Outlets ...................................................................................... 25

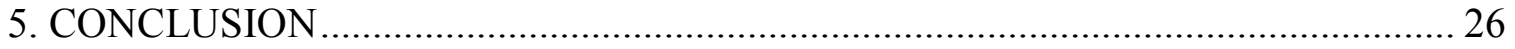

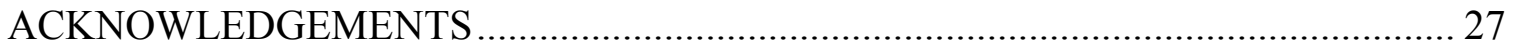

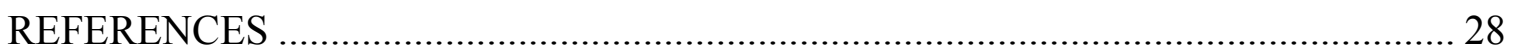

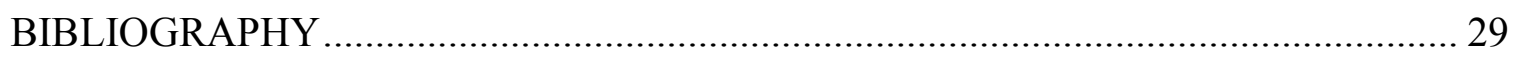

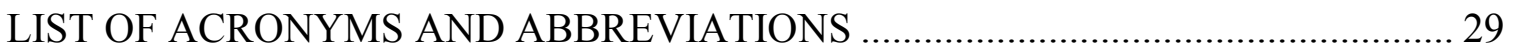

\section{$\underline{\text { LIST(S) OF GRAPHICAL MATERIALS }}$}

Fig. 1.1 Schematic of a SiC field-effect sensor for $\mathrm{H} 2$ containing gases 6

Fig. 3.1.1 Schematic cross section of the MISiC capacitor 8

Fig. 3.2.1a Block diagram of sensor control and data acquisition $\quad 10$

Fig. 3.2.1b User interface of constant-cap_Boonton-09.exe 11

Fig. 3.2.2a Block diagram of data acquisition set-up $\quad 12$

Fig. 3.2.2b User interface of Fast_Acquisition-01.exe 13

Fig. 3.2.2c Data flow of time resolved acquisition program $\quad 14$

Fig. 3.2.2d Analog feedback circuit $\quad 15$ 
Fig. 3.2.3a Block diagram of sensor control program $\quad 15$

Fig. 3.2.3b User interface of the sensor control program $\quad 16$

Fig. 3.2.5 Block diagram of the two programs together 17

Fig. 3.3a Schematic of the fast gas sensor measurement apparatus 18

Fig. 3.3b Photos of the fast gas sensor measurement apparatus 19

Fig. 3.4.1 Temperature-programmed desorption 20

Fig. 3.4.1 Simulated temperature-programmed desorption data 21

Fig. 3.4.3 UHV sample mount 22

Fig 4.1.1 X-ray diffraction scans of Pt sensing layers deposited on oxidized $\mathrm{SiC} \quad 24$ 


\section{INTRODUCTION}

Emissions control for the energy sector requires gas sensors that can operate in chemically reactive high temperature environments for both real time monitoring and feedback control of exhaust products. Gaseous species that need to be monitored include hydrogen, hydrocarbons, nitrogen oxides and sulfur oxides. Metal / insulator / semiconductor structures with catalytically active gates are widely used to electronically detect the presence of various chemical species [Spetz 2001]. The wide bandgap semiconductor silicon carbide, $\mathrm{SiC}$, enables device operation to temperatures in excess of $1200 \mathrm{~K}$. In the case of the $6 \mathrm{H}$ polytype the energy gap is $3.0 \mathrm{eV}$, compared to $1.1 \mathrm{eV}$ for silicon. These field-effect devices require a robust dielectric to enable modulation of the semiconductor carrier concentration via an applied gate potential. $\mathrm{SiC}$ has a native oxide, $\mathrm{SiO}_{2}$, which fulfills this need. In addition, $\mathrm{SiC}$ is chemically stable in reactive environments making it well suited for sensing applications in harsh environments.

Refractory metal gate $\mathrm{SiC}$ devices have been demonstrated for high temperature chemical sensing application by a number of groups [Spetz 2001, Filippov 1999, Hunter 2000, Kim 2001, Nakagomi 2001, Samman 2000, Serina 2001, Ghosh 2002]. These include hydrogen and hydrocarbon sensors operating at temperatures from $600 \mathrm{~K}$ to $1300 \mathrm{~K}$. Specific sensor configurations have achieved millisecond time response and sensitivity at the $0.1 \%$ level. The fast response makes the sensors suitable for feedback control. In addition, there are preliminary indications that suitably designed devices may offer sensitivity to ammonia, carbon monoxide, nitrogen oxides and fluorocarbons.

The operation of field-effect devices is dominated by electronic interactions at interfaces. In the case of a metal/insulator/SiC (MISiC) structure, these interfaces are the environment/metal interface, the metal/oxide interface and the oxide/semiconductor interface, which will be studied using a number of spectroscopic techniques. For the $\mathrm{SiC}$ sensor technology to fulfill its potential in real world applications the issues of reliability and stability need to be addressed, which requires a detailed experimental study of hydrogen transduction following dehydrogenation at the heated catalytic gate.

A schematic of our catalytic gate SiC field-effect sensor for hydrogen containing species is shown in Figure I.1. Refractory metal gates such as Pt, Pd and Ir can efficiently dehydrogenate long chain hydrocarbons at temperatures above $700 \mathrm{~K}$. Following dehydrogenation at the heated gate, hydrogen diffuses into the structure. For a Si based catalytic gate sensor operating below $500 \mathrm{~K}$ it has been shown that hydrogen gives rise to a polarized layer at the metal/oxide interface [Lundstrom 1976]. This chemically induced polarization charge results in a simple lateral shift of the $\mathrm{C}-\mathrm{V}$ or current-voltage (I-V) characteristic of the capacitor or Schottky diode sensor,

respectively. The magnitude of the voltage shift in these Si based sensors is a measure of the chemically modified metal/semiconductor barrier height. It has been assumed that the same mechanism describes the operation of higher temperature $\mathrm{SiC}$ based sensors for hydrogen containing species. At temperatures above $700 \mathrm{~K}$ the diffusion time for hydrogen through $100 \mathrm{~nm}$ of $\mathrm{Pt}$ and $50 \mathrm{~nm}$ of $\mathrm{SiO}_{2}$ is less than $5 \mu$ s [Katsuta 1979] and $0.5 \mathrm{~ms}$ [Beadle 1985] respectively. We have previously demonstrated via in-situ C-V spectroscopy of $\mathrm{Pt} / \mathrm{SiO}_{2} / \mathrm{SiC}$ sensors at $800 \mathrm{~K}$ that oxidizing species affect the electronic properties of both the metal/oxide and oxide/semiconductor interfaces [Tobias 2003A]. 


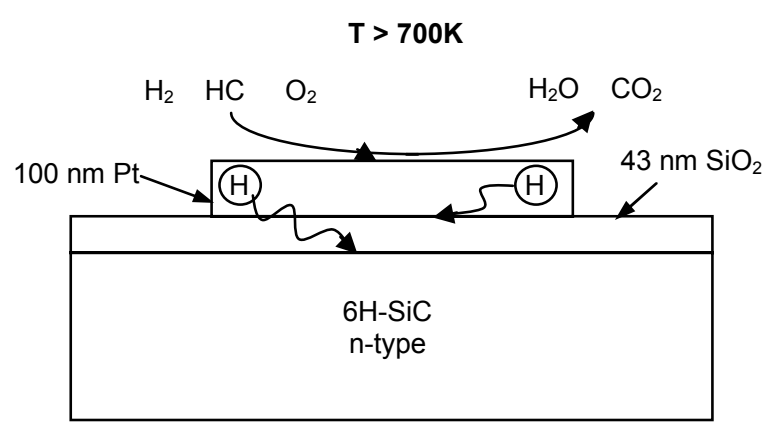

Fig. 1.1 Schematic of a catalytic gate SiC field-effect sensor for hydrogen containing gases. Typical operation is at $\mathrm{T}>700 \mathrm{~K}$. Hydrogen can diffuse to both the metal/oxide and oxide/semiconductor interfaces. 


\section{EXECUTIVE SUMMARY}

A silicon carbide ( $\mathrm{SiC}$ ) based sensor for the detection of power plant combustion products is been developed. The sensor is a catalytic gate field effect device that can detect hydrogen containing species in chemically reactive, high temperature environments. $\mathrm{Pt} / \mathrm{SiO}_{2} / \mathrm{SiC}$ devices were fabricated on commercially purchased single crystal wafers. Sputtering and electron beam evaporation techniques were developed to deposit the metallic platinum sensing layer that can withstand repeated cycling to $900 \mathrm{~K}$ without delamination. From x-ray diffraction measurements we have determined that our Pt layer are highly textured (111) films, which contributes to the high temperature stability and adhesion of the sensing layer to the underlying oxidized $\mathrm{SiC}$ substrate.

User friendly software has been developed for testing the $\mathrm{SiC}$ sensor at the site of an application, such as a model scale energy plant at NETL. The software can be run from a laptop computer for portability. An apparatus for measuring fast sensor responses (in the millisecond regime) has been built and tested. Software for regulating a fast sensor and for recording its signal has been developed and tested.

Experimental equipment and techniques are under development for ultrahigh vacuum surface science studies of the catalytic gate. Alumina substrates for mounting and making electrical contact to samples in UHV have been designed and ordered. A normalization technique has been identified that eliminates a problematic interference between the sample heating system and the mass spectroscopic system used for temperature-programmed desorption.

From a project management perspective, a postdoctoral researcher has been hired to work on the surface science program at Tufts University, starting June 1, 2004. This start date is later than originally projected, and as a result progress in this phase has been slower than expected. At Michigan State University, the postdoctoral researcher who was previously working on the project, Dr. Peter Tobias, has continued with the project and developed the fast sensor test along with the associated software during the current reporting period of October 2003 to March 2004. Dr. Tobias is currently searching for a permanent industrial position and plans to continue with the project on a month by month basis. An offer was made to a second researcher for the sensor measurements portion of the project, which he declined in favor of a faculty position. The search for a suitable postdoctoral researcher at MSU will continue into the next project period. Two oral presentations were made during this reporting period. Dr. Ruby Ghosh presented a paper entitled "High temperature $\mathrm{SiC}$ chemical sensors: an in-situ study of gas response mechanisms" at the 2003 International Symposium on SiC and Related Materials, Oct 5 Oct 10, 2003 in Lyon, France. Dr. Peter Tobias presented a paper entitled "Sensing mechanisms of SiC devices for exhaust gas applications" at the second IEEE International Conference on Sensors, Oct 21 - 24, 2003 in Toronto, Canada. His paper was presented in a special session on "Extreme Environment Chemical Sensors" organized by Dr. Ghosh. 


\section{EXPERIMENTAL}

\subsubsection{Samples}

For our high temperature sensors, we prepare silicon carbide based metalinsulator-semiconductor devices (MISiCs) as capacitors. The cross section of the finished capacitors is shown in Fig. 3.1.1. The SiC wafers are obtained commercially from Cree, Inc [Cree]. The thermal oxide is prepared by Cree, Inc. or by the group of J. Cooper at Purdue University. The oxide is grown at Cree in dry oxygen at $1470 \mathrm{~K}$ [Lipkin 1996], and at Purdue in wet oxygen at $1420 \mathrm{~K}$, followed at both locations by a wet anneal at $1220 \mathrm{~K}$. The samples are then sawed into $1 \mathrm{~cm} \mathrm{x} 1 \mathrm{~cm}$ pieces. While being sawed, the samples are protected with photoresist that is afterwards removed with Nanostrip(C. The sample are then covered with photoresist only on the front side, the back oxide is etched off in buffered hydrogen fluoride solution, and the photoresist is removed with Nanostrip $\mathbb{C}$. All chemicals used are CMOS grade.

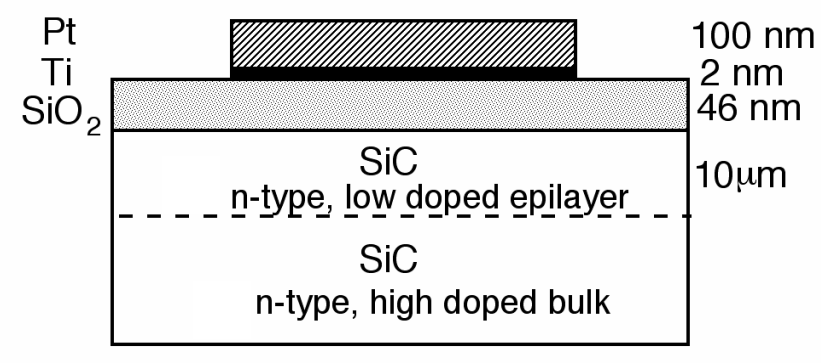

Fig. 3.1.1 Schematic cross section of a MISiC capacitor. Pt is deposited on a thermally oxidized $\mathrm{SiC}$ substrate with dot diameters from 200 to $1000 \mu \mathrm{m}$. Some samples had an intermediate layer of Ti. The Pt thickness was $100 \mathrm{~nm}$ for the sensor and capacitance measurements. 


\subsubsection{Metal deposition}

The interface between the metal and the insulator is critical both for gas sensing and for metal adhesion, which is important for sensor reliability. To get a sharp and reproducible interface, we cleaned the sample prior to metal deposition by the RCA method: We clean the samples in a solution of conc. $\mathrm{NH}_{3}, 30 \%-\mathrm{H}_{2} \mathrm{O}_{2}$ and $\mathrm{H}_{2} \mathrm{O}(1: 1: 6)$ at $75{ }^{\circ} \mathrm{C}$ for 20 min and, after rinsing with distilled water, then in a solution of conc. $\mathrm{HCl}$, $30 \%-\mathrm{H}_{2} \mathrm{O}_{2}$ and $\mathrm{H}_{2} \mathrm{O}(1: 1: 7)$ at $75^{\circ} \mathrm{C}$ for another $20 \mathrm{~min}$. At the end, the samples are rinsed with distilled water and left in the water until metal deposition. The chemicals used for cleaning are from T.J. Baker, CMOS grade.

After being thoroughly rinsed and blown dry with nitrogen, metal dots are deposited on the front side of the samples through a shadow mask at a temperature of $600-650 \mathrm{~K}$. The metal thickness is $\sim 100 \mathrm{~nm}$ for the capacitance and sensor

measurements. We have used three types of shadow masks with dot areas from $3.1 \times 10^{-8}$ up to $1.6 \times 10^{-5} \mathrm{~m}^{2}$, giving us arrays of 20 to 50 sensors per $\mathrm{SiC}$ chip. The metal was deposited by either e-beam evaporation or sputtering in argon at a pressure of $0.33 \mathrm{~Pa}$. The e-beam evaporated films consist of a single layer of platinum. The sputtered films are either platinum or platinum on top of a $2 \mathrm{~nm}$ thick titanium intermediate layer. The precision of the thickness monitors in the deposition chambers is checked in regular intervals with a Dektak profilometer. Each dot is the gate of a metal-insulator-silicon carbide capacitor (MISiC).

\subsubsection{Contact to the metal gates}

Electrical contact to the metal gates was made by using an ultrasonic wire bonder from Kulicke and Soffa. The SiC sample was glued to an alumina header with gold pads. Prior to bonding the $\mathrm{Pt}$ gates on the $\mathrm{SiC}$ substrate were always rinsed with isopropanol (CMOS grade). The sample was heated to $600 \mathrm{~K}$ on a hot chuck. Gold wire, 25 um in diameter, was first bonded to the gold pads on the header then to the Pt capacitor gates. The critical bond is the one made to the Pt gate. For proper adhesion, we found it necessary to bring the tool down on the Pt gate, hold it in place for $10 \mathrm{~s}$, and then apply the ultrasonic power to make the bond.

\subsubsection{X-ray diffraction measurements}

X-ray diffraction measurements were made on a RIGAKU 200B rotating anode diffractometer with a small and large angle scattering goniometer. The X-ray source is a copper target. The instrument measures theta - two theta spectra in reflection. The SiC samples were mounted on a specially fabricated holder that enables us to accurately reference the front surface of the sample with the plane of the diffractometer. The spectra were compared with data from the CIME data base (http://cimesg1.epfl.ch/CIOL/ems.html). 


\subsection{Time Resolved Fast Sensor Test Assembly}

The following hardware and software for making time resolved measurements on sensors heated up to $900 \mathrm{~K}$ were developed. We have developed the software in the programming language Labview to characterize our sensors on different time scales. After each measurement, a data file with extension .dat is saved with the bias voltage, the capacitance and the conductance at the recorded times. The settings of the measurements are saved in an additional file with extension .set. In addition to our manuals for the measurement set-ups, the user-interfaces of the programs provide strips explaining each button with a short expression: a person with experience in sensor testing should be able to use the programs intuitively.

The hardware used for testing all programs was a desktop PC with a PCI-GPIB card from National Instruments and the card 6036E from National Instruments with 16bit multifunction I/O, 16 inputs, and 2 outputs.

We present a new apparatus for measuring the response times of a gas sensor with millisecond resolution, while also capturing the slower components of the response such as the steady state value. To make full use of the new apparatus, we have optimized the software to be able to record sub-millisecond signals.

\subsubsection{Program for sensor control and data acquisition}

For sensor measurements at real application sites, we have developed a program for sensor control and data acquisition. The required hardware is a PC with operation systems Windows XP or 2000 and with a GPIB-card, e.g. from National Instruments, a GPIB cable and the 7200 capacitance meter from Boonton, see Fig. 3.2.1a. For flexibility in harsh measurements environments, a laptop can be used as the measurement computer. The program is intended for applications that don't require the recording of sensor responses in the millisecond range.

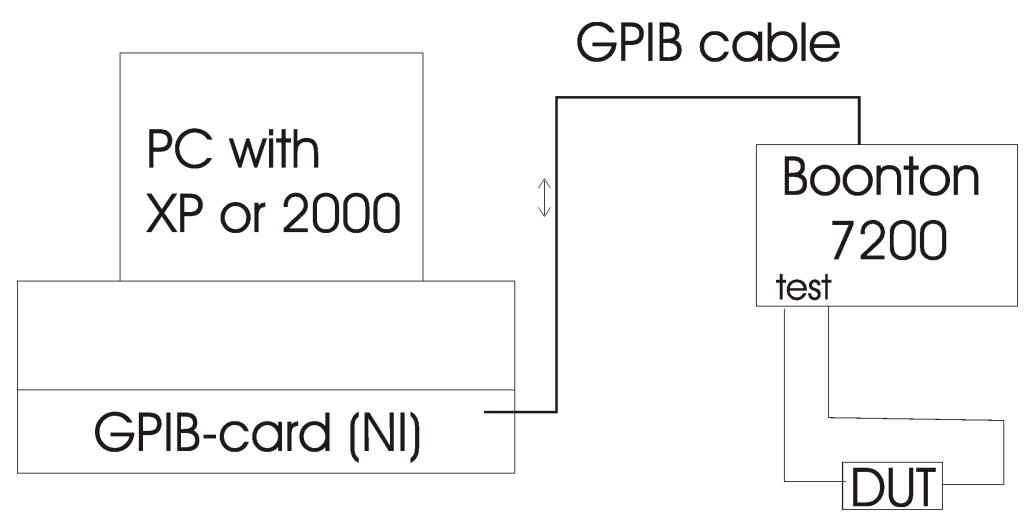

Fig. 3.2.1a Block diagram of sensor control and data acquisition. Arrows indicate the flow of data.

The sample is connected to the test contacts of the Boonton, and the PC via the GPIB controls the Boonton capacitance meter. This communication, however, is too slow for 
millisecond resolutions. The program is started on the PC, opening the window in Fig. 3.2.1b.

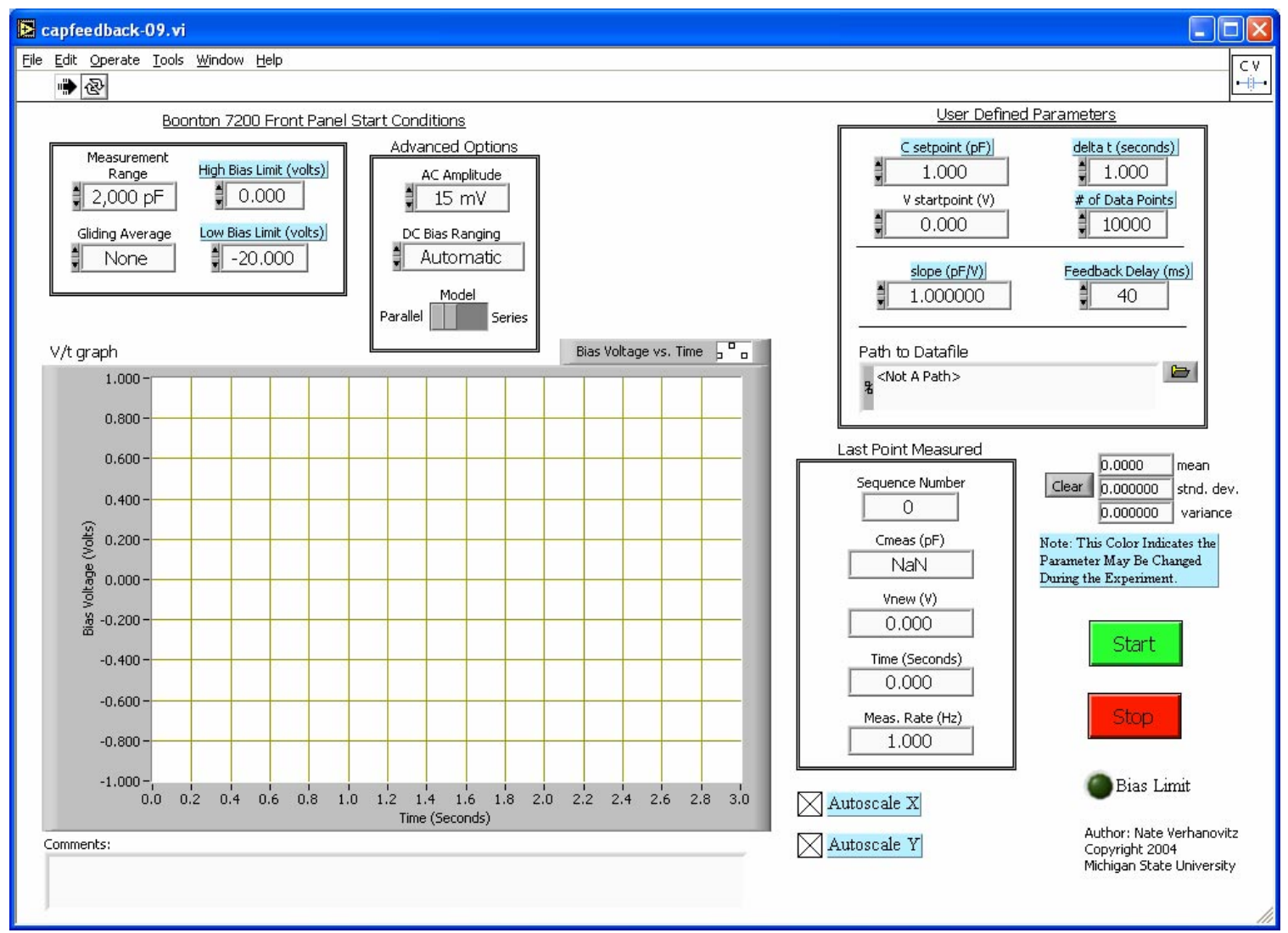

Fig. 3.2.1b User interface of constant-cap_Boonton-09.exe. The user enters the operation parameters for the Boonton capacitance meter (top left) and parameters for the sensor and the saved data (top right).

For optimal performance, the measurement range should be as small as possible. The start voltage should be close to the expected sensor signal and the limits to the bias voltages should be chosen to prevent damage for the sample. If a faster signal is preferred and some noise can be accepted, the gliding average and the feedback delay should be small, and the slope should be just above the actual slope at the set point. If a quieter signal is preferred, the gliding average should be large; therefore, also the feedback delay, making the signal also slower, and the slope can be a bit larger.

\subsubsection{Time resolved data acquisition program}

For the recording of data with sub millisecond resolution, we have developed a program for time-resolved data acquisition. The required hardware for using the program in sensor measurements is a PC with operating system Windows XP or 2000 and with a card that is connected to a BNC board (BNC-2110, Nat. Instruments). 


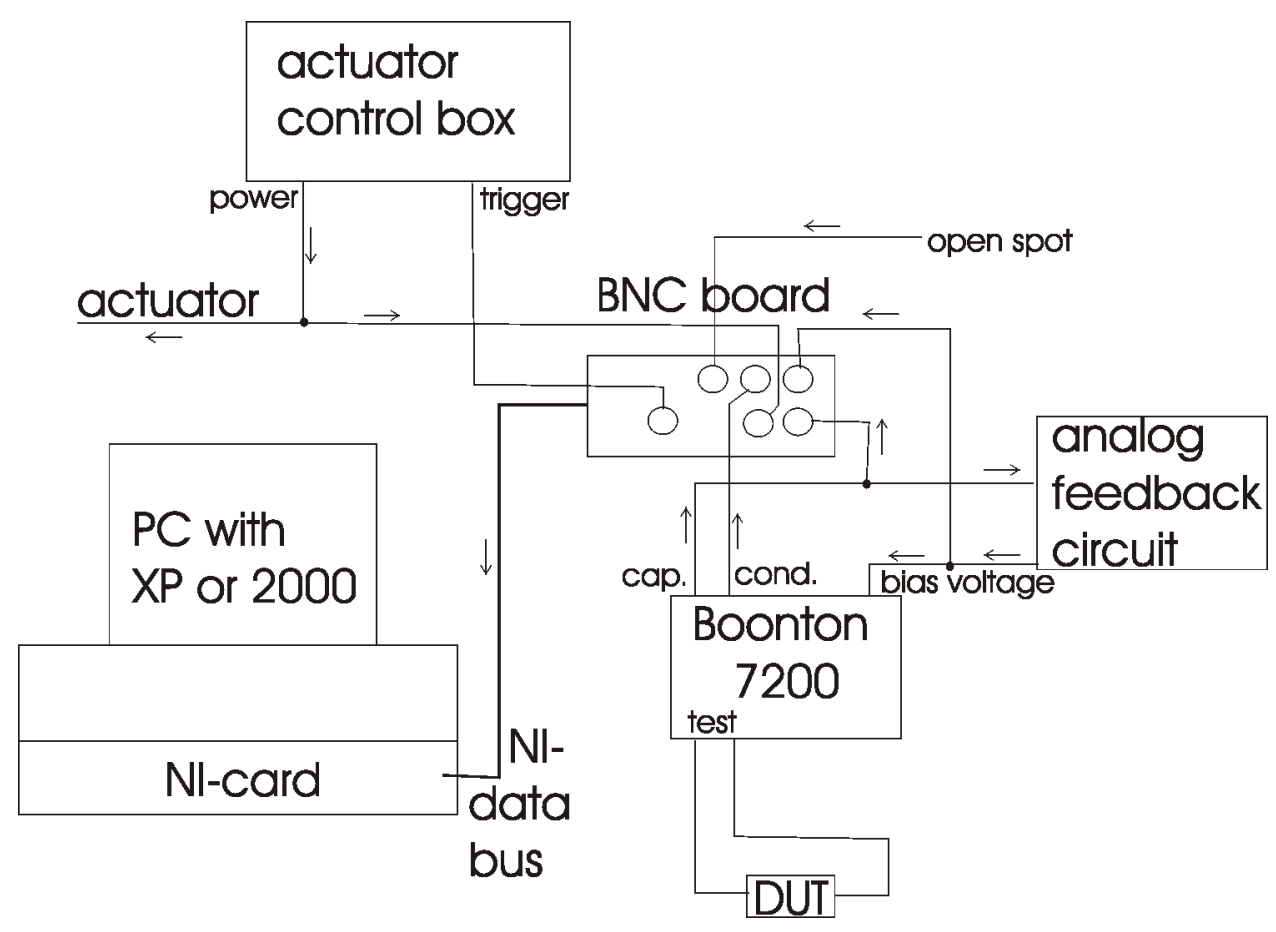

Fig. 3.2.2a Block diagram of data acquisition set-up when controlling the sensor with an analog feedback circuit. Necessary for the program are the PC with the card and cable and the BNC-board (BNC-2110, Nat. Instr.). Arrows indicate the flow of data and voltages.

The actuator control box switches the actuator that controls the ambient gas of the sensor and sends a trigger to the BNC-board. The analog feedback circuit receives the capacitance of the sensor from the capacitance meter as a voltage and regulates the bias voltage to keep the capacitance at a constant set point. The BNC board receives the trigger and the card starts recording. The open spot on the BNC board is available to monitor an additional signal, e.g. the actuators current or a sensor for the position of the moving gas outlets. 


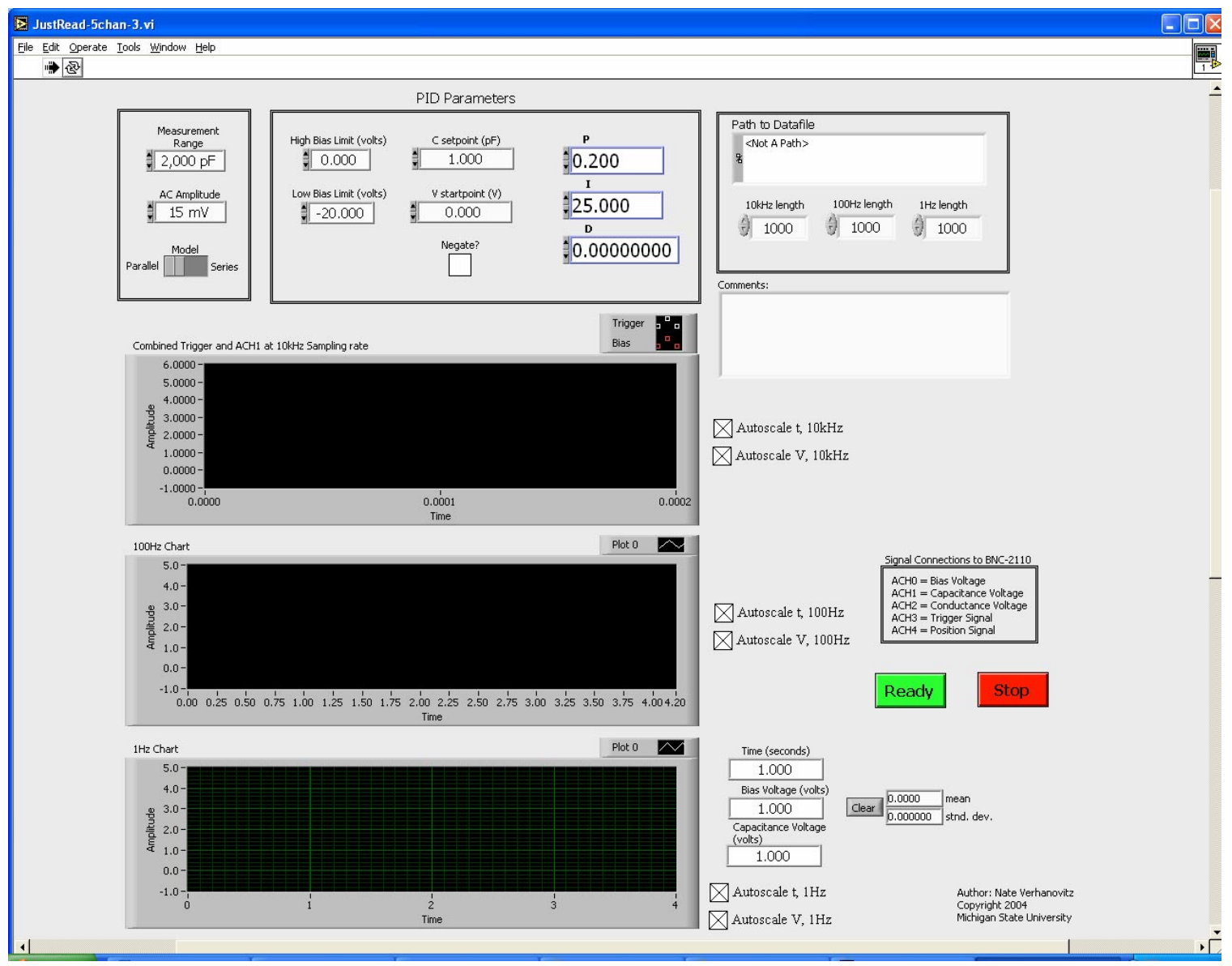

Fig. 3.2.2b User interface of Fast_Acquisition-01.exe. The user enters the values of parameters that have been set manually into the capacitance meter or another program, called sensor control program (3.2.3). The user also chooses how many data points should be stored at the three sampling frequencies of $10 \mathrm{kHz}, 100 \mathrm{~Hz}$, and $1 \mathrm{~Hz}$ (top right). 


\section{Flow of fast aquisition program}

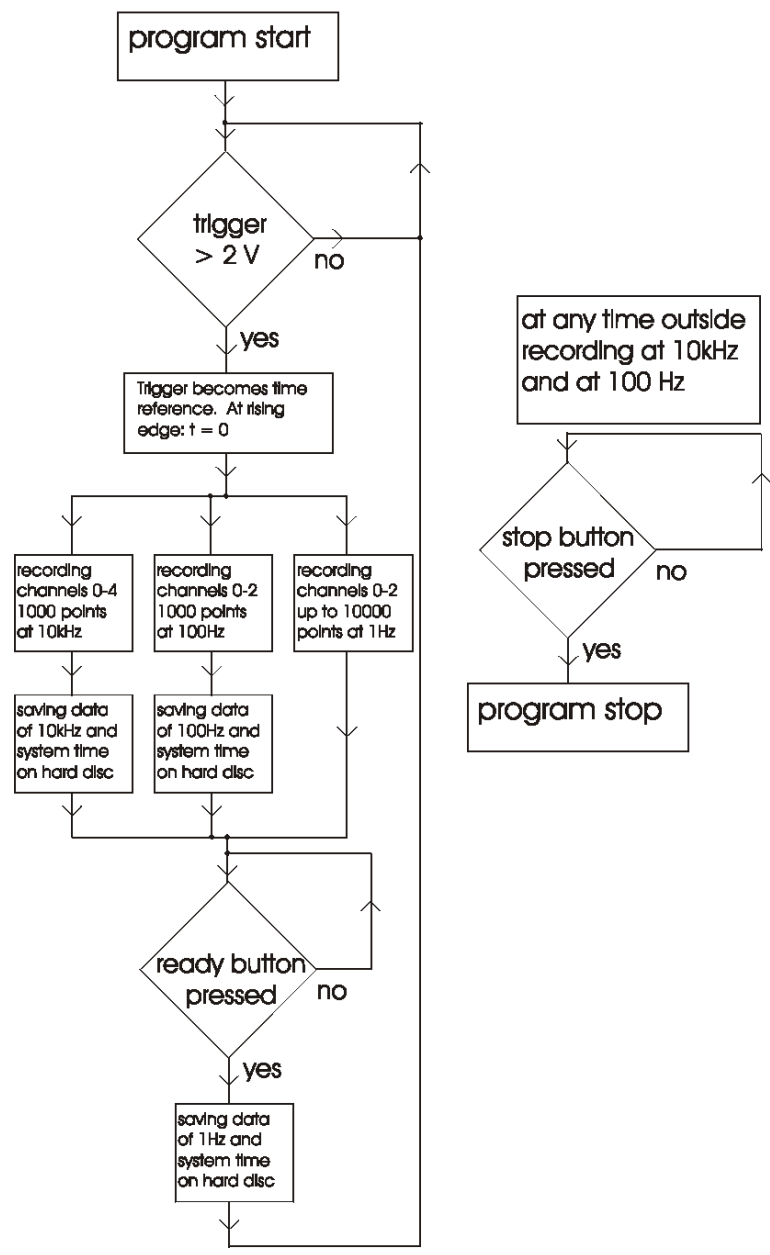

Fig. 3.2.2c Data flow of time resolved acquisition program. The program saves the data each time after a trigger signal, the number of which is not limited. Upon stopping, the program saves also the entered settings.

Part of the diagram in Fig. 3.2.2a is the analog feedback circuit that regulates the bias voltage to keep the capacitance of the sample constant. The measured response to a step like change of a sample's electrical characteristics was an exponential relaxation with a response time of $0.42 \mathrm{~ms}$. 
Circuit for keeping the measured capacitance

constant by changing the bias voltage

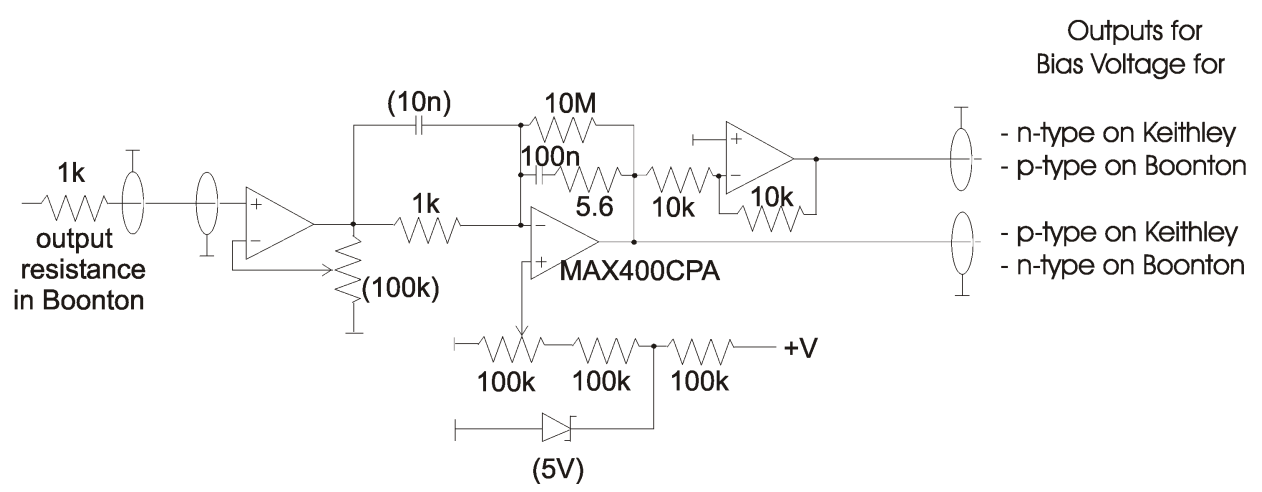

Fig. 3.2.2d Analog feedback circuit. The signals are processed from left to right. Values in parentheses have not yet been installed. Any deviation from the pre-set value of the capacitance reaches the OpAmp MAX400CPA through a $1 \mathrm{kOhm}$ resistor and is responded to through the $100 \mathrm{nF}$ capacitor.

\subsubsection{Sensor control program}

We have also developed a program that could replace the analog circuit in Fig.3.2.2d. The program uses proportional intergral differential (PID) control for keeping the capacitance constant by regulating the bias voltage. The program does not store any data, neither measured nor manually entered.

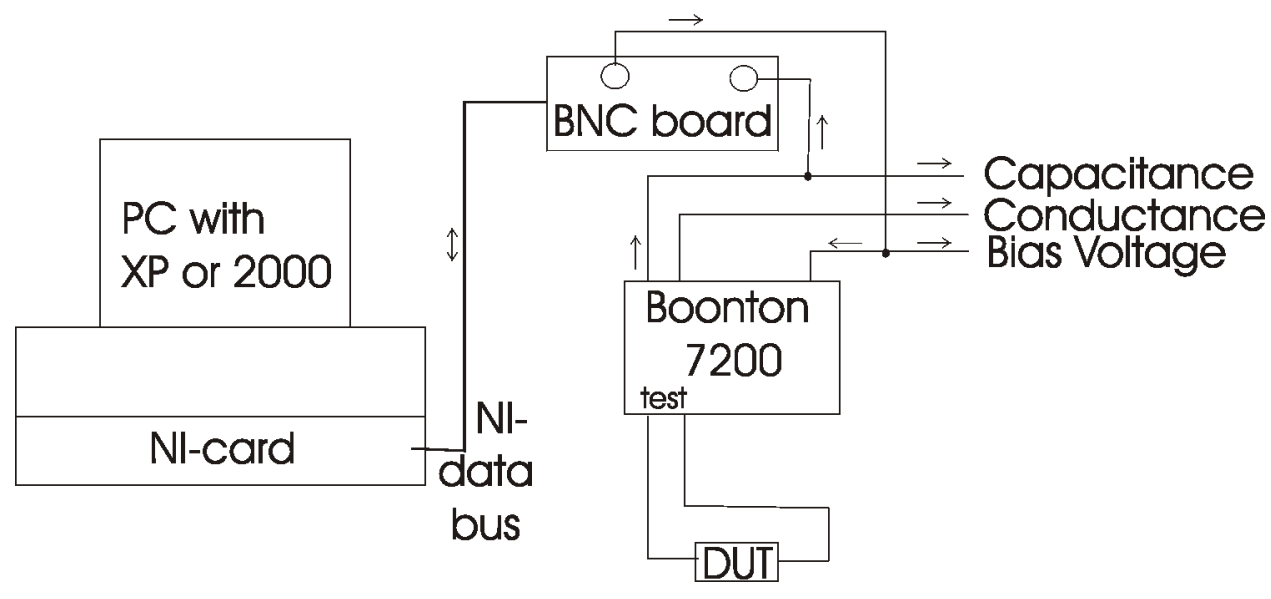

Fig. 3.2.3a Block diagram of sensor control program. Arrows indicate the flow of information and voltages. The program regulates the bias voltage to keep the capacitance constants, and provides three voltages, for capacitance, conductance, and bias voltage to be recorded by another program or an oscilloscope. The BNC board is BNC-2110 from Nat. Instr. 


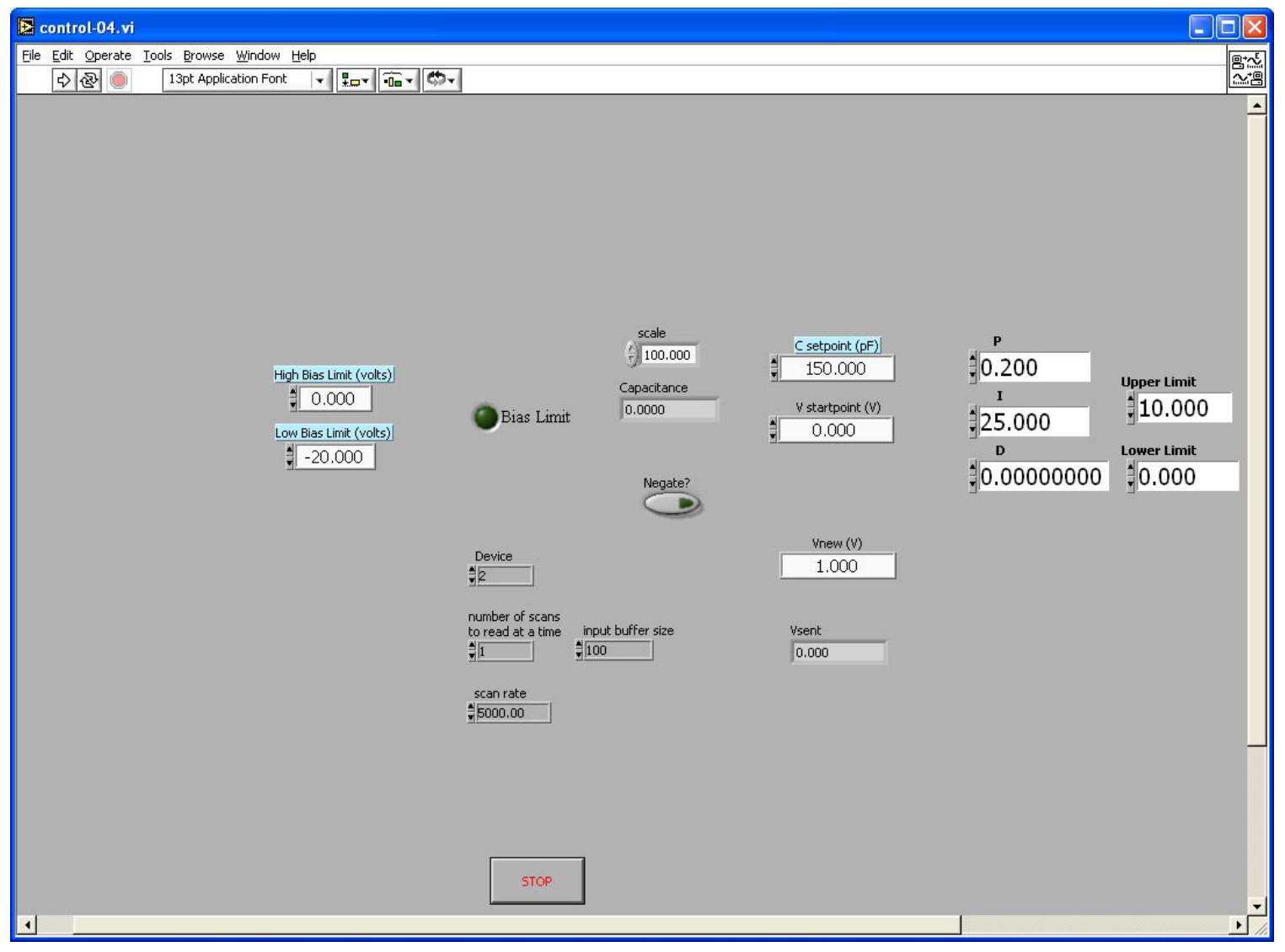

Fig. 3.2.3b User interface of the sensor control program. The user defines the capacitance set point, the start voltage, and the control parameters P, I, and D to be used. To protect the sample from too high voltages, the bias voltage range should be limited.

\subsubsection{Fast automated control and data acquisition}

With our present cards, we need two computers to run the two programs, the time resolved data acquisition program and the sensor control program. With faster cards, the two functions might be concentrated in one computer only. 


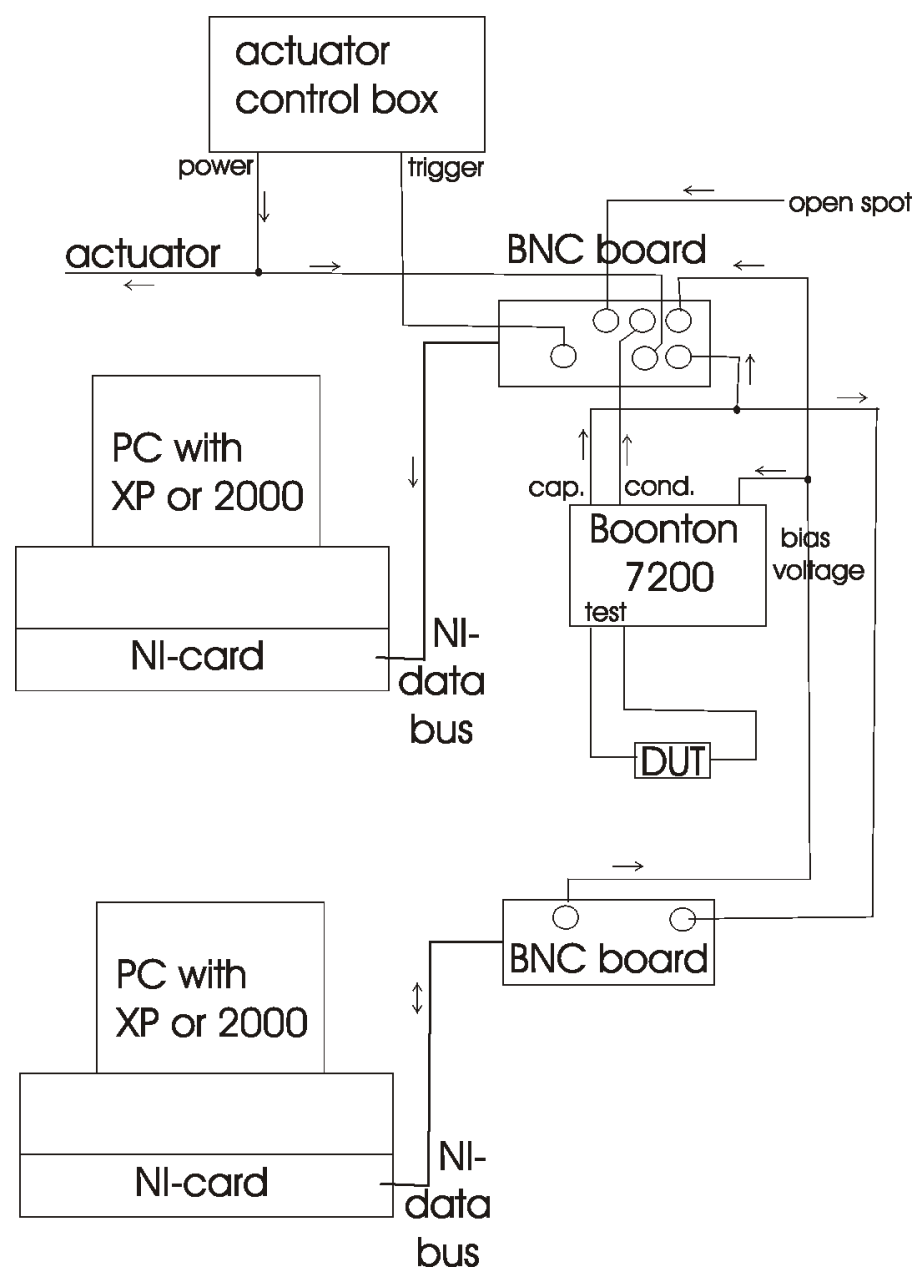

Fig. 3.2.5 Block diagram of the two programs together. Arrows indicate the flow of information and voltages. The BNC-board is the BNC-2110 from Nat. Instr. 


\subsection{Moving Gas Outlets}

The principle of the new apparatus for measuring sensor response times within the millisecond range is shown in Fig. 3.3a

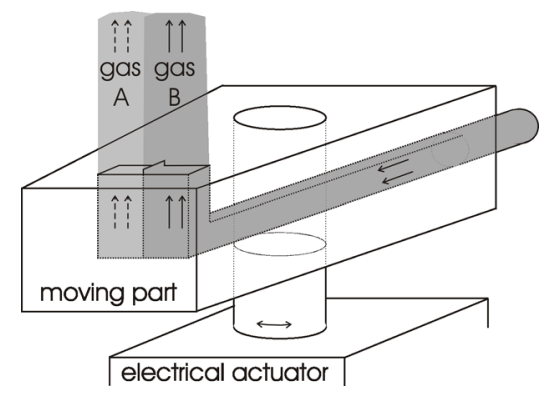

Fig. 3.3a Schematic of the fast gas sensor measurement apparatus. The sensor (not shown) is mounted face down, above either gas jet A or B. In the "moving part", the jets are separated by a thin barrier, extending $0.4 \mathrm{~mm}$ above the surface. The electrical actuator (Densitron, DERL32) can rotate the moving part between two stable positions. The actuation translates the gas outlets by $2.2 \mathrm{~mm}$ in $1 \mathrm{~ms}$, thereby switching the gas under the sensor.

The apparatus is a continued development of the set-up presented in [Tobias, 1999]. In the old set-up, the sensor was exposed to one gas for only $20 \mathrm{~ms}$ before the ambient gas of the sensor changed again. Therefore, only fast components of the sensor response could be monitored, and the slow contributions to the sensor response were lost. The steady state signal couldn't be measured at the same time as the fast responses, because for steady state both streams had to be switched to the same gas. In our current setup we will be able to monitor and record both the fast (down to $1 \mathrm{~ms}$ ) and slow components of the sensor response. Note that the time resolved data acquisition program, described in 3.2.2, allows us to simultaneously store data at $10 \mathrm{KHz}$ (for the fast component) and 100 $\mathrm{Hz}$ and $1 \mathrm{~Hz}$ (for the slow component).

For driving the electromagnetic actuator, we use a self-built circuit that provides us with a short pulse of about $25 \mathrm{~V}$ and $1 \mathrm{~A}$ and a simultaneous trigger pulse. 

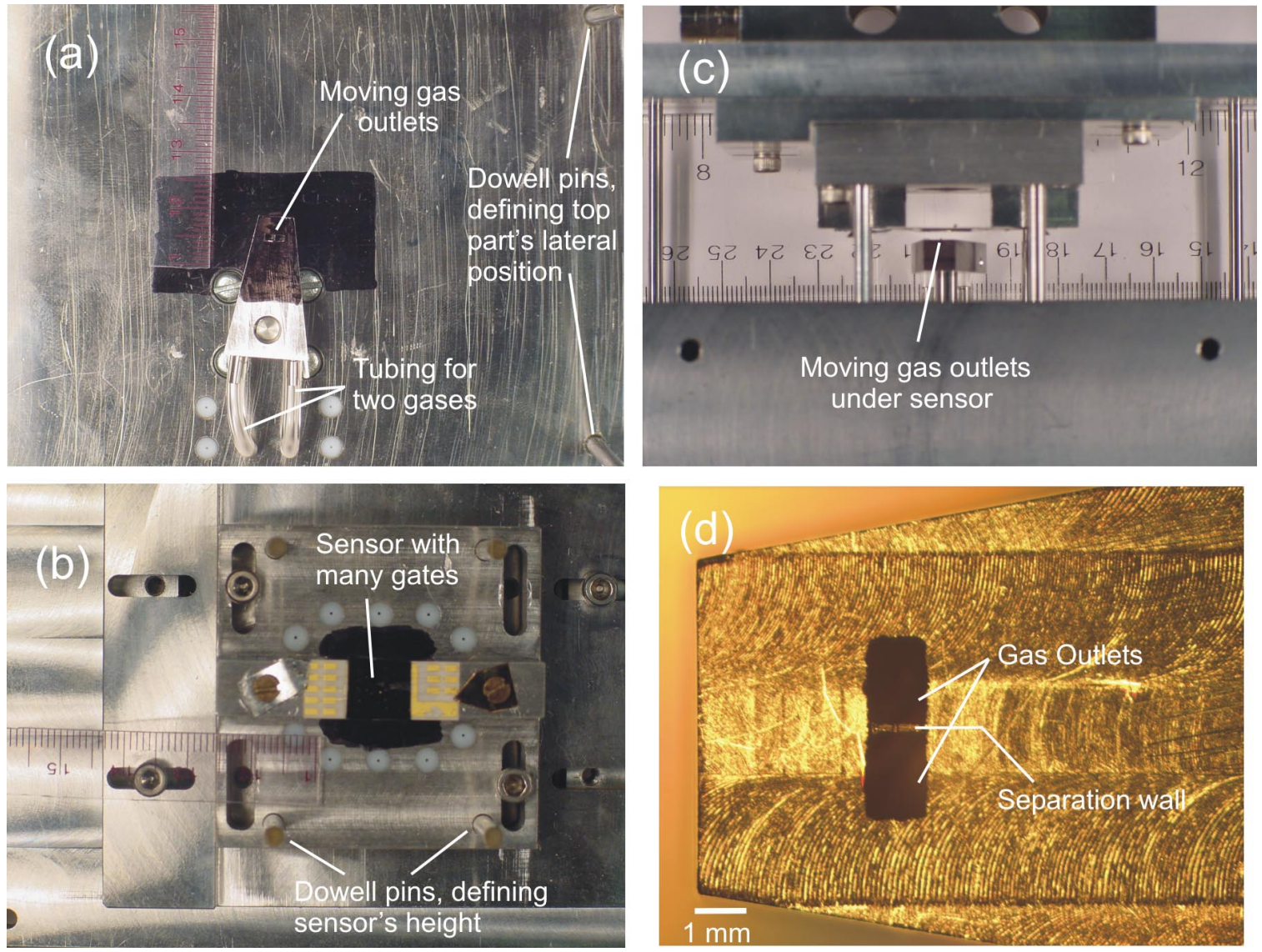

Fig. 3.3b Photos of the apparatus: bottom part (a), top part (b) and the two parts together (c), with the rulers showing centimeters. The moving gas outlets $(\mathrm{d})$ are with the electromagnetic actuator in the bottom part. The sample is mounted on the top part. Part of the set-up was painted black to reduce reflections in a planned fluorescence experiment. Each gas outlet has a size of $1 \mathrm{~mm} \times 1.7 \mathrm{~mm}$, the separation wall between them extends to $0.4 \mathrm{~mm}$ above the surface (d).

An important parameter of the experiment is the distance between moving gas outlets and the sensor. It can be adjusted to within a 50 um by mounting the moving gas outlets on the rotating shaft of the actuator in different heights. Typical distances are between 0.7 and $1.0 \mathrm{~mm}$. The sample mounting on the top part with two sliding plates allows the precise positioning of the sample above the moving gas outlets within $0.2 \mathrm{~mm}$. The wide opening of the gas outlets makes it possible to characterize every flat sensor with a diameter up to $1 \mathrm{~mm}$. 


\subsubsection{Temperature programmed desorption}

One of the most useful techniques in surface chemistry is temperatureprogrammed desorption (TPD), illustrated schematically in Fig. 3.4.1. The sample is exposed to one or more gases at a sufficiently low temperature (typically $\sim 100 \mathrm{~K}$ ) that the gases stick to the surface and do not react. The sample is then heated at a linear rate, $d T / d t \sim 5 \mathrm{~K} / \mathrm{s}$, and the gases evolved from the surface are detected with a quadrupole

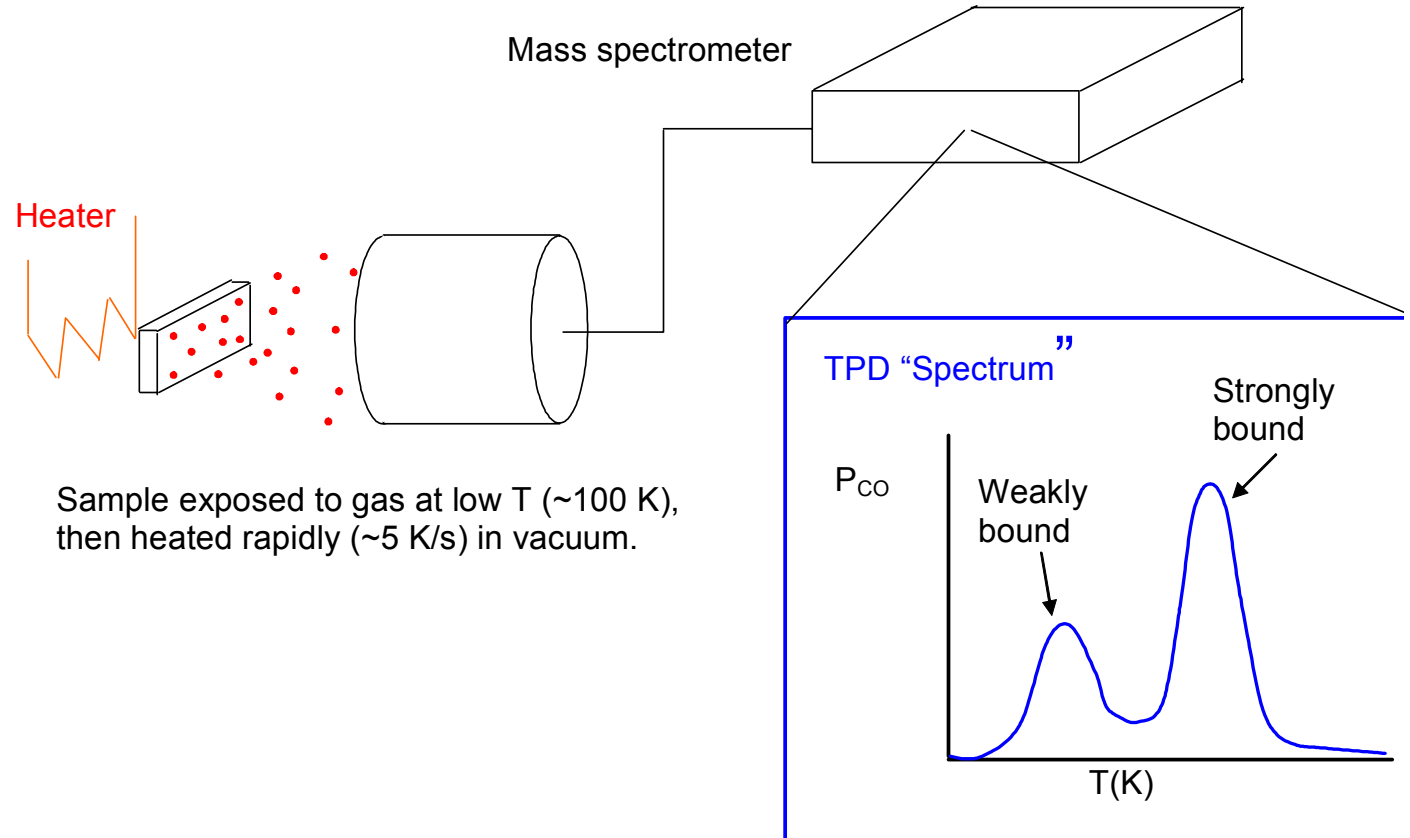

Fig. 3.4.1 Temperature-programmed desorption: Schematic representation of the technique.

mass spectrometer (QMS). This simple and widely used method can provide a great deal of information about surface coverages, binding energies, binding sites, and surface reactions.

Rapid heating to high temperatures is achieved by electron bombardment. A filament behind the sample is resistively heated and biased at a negative potential of several hundred volts relative to the sample, which is at or near ground potential. Electrons thermionically emitted from the filament are accelerated by the electric field between the filament and the sample, and their kinetic energy is deposited in the sample on impact, providing high-power, easily controlled heating at relatively low currents.

In our system we have observed an interaction between the heating system and the mass spectrometer that impedes our ability to obtain accurate TPD measurements. This effect is shown in Fig 3.4.2, which displays the QMS signal for masses 2 and $3 \mathrm{u}$ as a function of time during sample heating. In this experiment the sample was not exposed to any gas, so no desorption is expected, and the signal at mass 3 , in particular, is definitely spurious, since no molecules with that mass should be present.

We have attempted to eliminate the spurious signals by surrounding the ionizer of the QMS with a wire grid cage that can be grounded or biased to eliminate stray electric 
fields or repel charged particles that may be produced by the electron beam. So far these efforts have been unsuccessful in reducing the spurious QMS signals. However we have been able to correct for the spurious signals using a normalization method described in section 4.5. Since the normalization method, though effective, is relatively inefficient requiring measurement of extra mass channels - we continue to look for a more robust solution.

\subsubsection{UHV sample mount design}

In preparation for making in situ capacitance measurements in ultrahigh vacuum, we have designed and ordered alumina substrates with thick-film gold pads for mounting and making electrical contact to $\mathrm{SiC}$ samples. These substrates are similar to those used in the MSU experiments, but with dimensions and contact pad layouts optimized for compatibility with the UHV sample mount shown in Fig. 3.4.3.

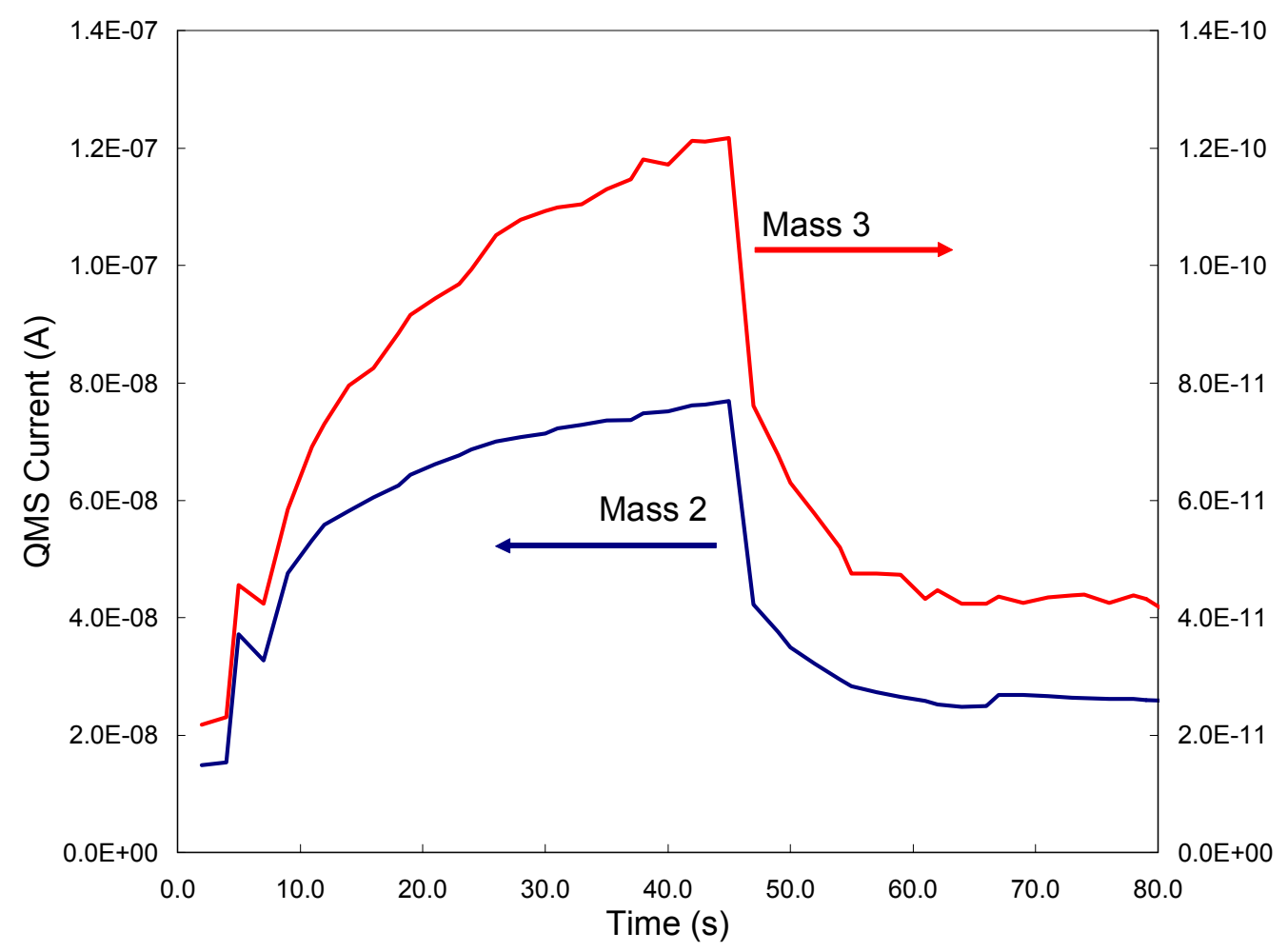

Fig. 3.4.2 Simulated TPD signals with no gas dosing, showing the spurious signal due to interference from the electron beam heater. The curves show raw QMS signals for mass 2 (hydrogen) and mass 3 (null signal). The apparent signal tracks the e-beam current, and the presence of a signal at mass 3 shows that it is an artifact. 


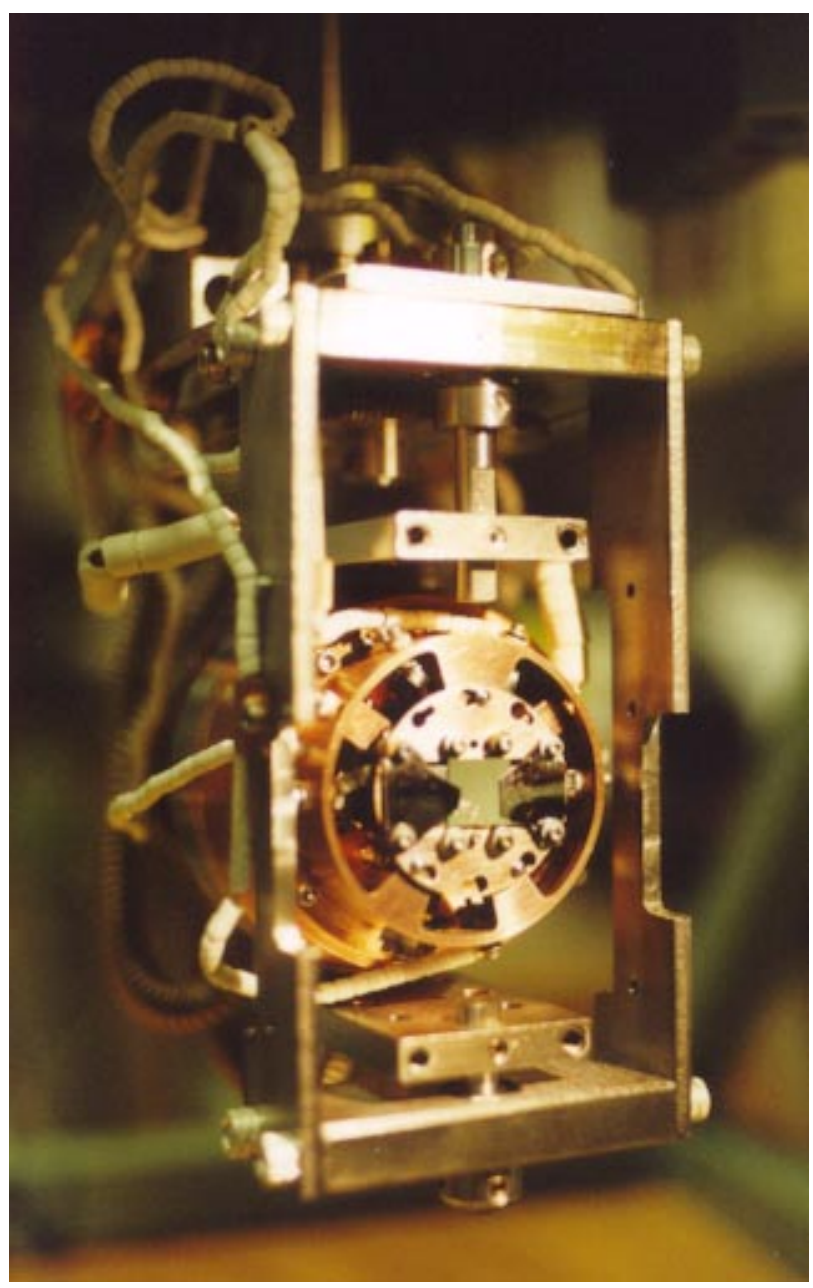

Fig. 3.4.3 UHV sample mount. The ring with keyhole slots is the sample carrier, which can be loaded in and out of UHV without breaking vacuum. A 1 $\mathrm{cm}^{2}$ prototype $\mathrm{Pt} / \mathrm{SiC}$ sample is shown clipped to the center of the ring. The mounting system permits sample heating and cooling (120 to >1200 K), and multiple electrical contacts. 


\section{RESULTS AND DISCUSSION}

\subsubsection{Reliability of metal films}

The reliability, in terms of adhesion, of the metal films was checked by two different temperature cycling measurements. The sample consisted of a large area $(\sim 9 \mathrm{~mm} \times 9 \mathrm{~mm})$ Pt film was deposited on an oxidized $\mathrm{SiC}$ substrate. In the first experiment gold wires were bonded to the corners of the sample. Four point probe measurements of the resistivity of the Pt film were performed up to $900 \mathrm{~K}$; the temperature dependent resistivity was consistent with that of bulk Pt. In the second experiment the film was cycled several times by heating rapidly to $1100 \mathrm{~K}$ in a UHV chamber. No signs of delamination were observed after the temperature cycling.

X-ray diffraction (XRD) measurements were also performed on Pt films deposited on both oxidized $4 \mathrm{H}-\mathrm{SiC}$ and $6 \mathrm{H}-\mathrm{SiC}$ substrates. As shown in the theta - two theta scans in Figure in 4.1.1, the Pt layer on either polytype is a highly oriented (111) Pt film, with respect to the surface normal. Pt has a face centered cubic (FCC) structure. When grown on an amorphous substrate, such as $\mathrm{SiO}_{2}$, the most common orientation is (111). Note that the $\mathrm{SiC}$ substrates are miscut with respect to the surface normal by $3.3^{\circ}$ in the case of $6 \mathrm{H}-\mathrm{SiC}$ and $8.1^{\circ}$ in the case of $4 \mathrm{H}-\mathrm{SiC}$. These misorientations were confirmed by performing theta XRD measurements. XRD data were obtained from several samples which were grown at different times (up to two years apart) using both e-beam and sputter deposition techniques. Regardless of the specifics of when and how the Pt film was deposited we find that they always grow with (111) texture. This demonstrates the long term reliability of our Pt film deposition techniques. We attribute both the high temperature adhesion and stability to thermal cycling of our Pt sensing films are due to the fact that we are able to deposit highly textured (111) Pt films on the oxidized SiC substrate. XRD measurements following thermal cycling are planned for the next reporting period. 

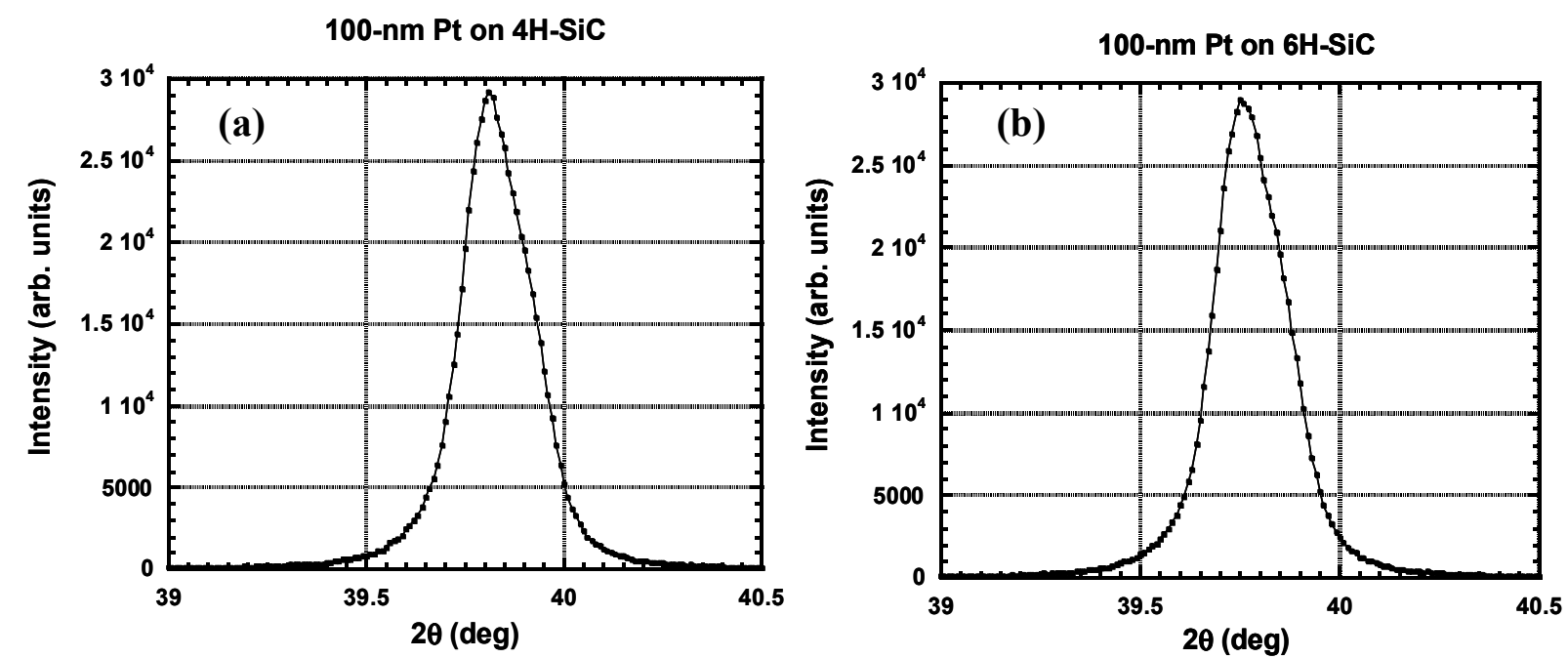

Fig 4.1.1 X-ray diffraction scans of Pt sensing layers deposited on oxidized SiC. (a) Sputtered Pt film on $4 \mathrm{H}-\mathrm{SiC}$ and (b) e-beam Pt film on $6 \mathrm{H}-\mathrm{SiC}$. The data shows that the Pt layers are highly textured (111) films grown normal to the sample surface.

\subsubsection{Reliability of device contacts}

We have successfully made electrical measurements on samples bonded with the techniques described in section 3.1.3. up to $900 \mathrm{~K}$. This temperature limitation is due to the upper limit of the home built coaxial cable in sample insert into the furnace tube. Previous experience indicates that this bonding technique should allow us to make electrical measurements up to at least 1000K [Larsson 2002].

\subsection{Time Resolved Fast Sensor Test Assembly}

On of the goals of the software we have developed for automating collection of data from the $\mathrm{SiC}$ sensors is that a person with experience in sensor testing should be able to use the program intuitively. This feature will be tested by using the software at a model energy plant in the Morgantown, WV NETL facility. The user-interfaces of the programs provide strips explaining each button with a short expression. We have also developed manuals for the various measurement setups.

The hardware and software was developed for making time resolved measurements on sensors heated up to $900 \mathrm{~K}$. Following are the results of the test we conducted to on the performance of the entire assembly. 


\subsubsection{Program for sensor control and data acquisition}

By using a large number for the gliding average, we can increase the stability of the signal of a sensor under constant conditions: the standard deviation of the signal was below $1 \mathrm{mV}$ for a gliding average of 100 . The response time to a change is under this circumstance in the order of ten seconds.

\subsubsection{Time resolved data acquisition program}

We have checked the function of the set-up in Fig. 3.2.2a while triggering the data recordings with the trigger signal from the actuator control box. The noise of the data was reduced with low pass filters with time constants of $0.1 \mathrm{~ms}$, corresponding to the fastest sampling frequency of $10 \mathrm{kHz}$. The power pulse is monitored through a low pass filter with a time constant of $0.3 \mathrm{~ms}$ to allow us to correlate better the actuation of the moving gas outlets to the changed sensor signal.

\subsubsection{Sensor control program}

We have successfully used the program to replace the analog feedback circuit even when working with a capacitance meter like the Keithley 595, whose time constant of $1 \mathrm{~ms}$ is markedly higher than the one of the Boonton 7200 with 50 us. Upon a steplike change of the electrical characteristics of the sample, the response times of the sensor voltage from 10 to $90 \%$ was about $1 \mathrm{~ms}$. The Keithley meter, albeit slower, gives more precise values for the capacitance, making it superior for sensor characterization by $\mathrm{C}-\mathrm{V}$ curves. We prefer the use of the same measurement set-up for $\mathrm{C}-\mathrm{V}$ curves and sensor measurements to a switch of instrumentation that may result in an artificial misalignment of measurement results.

\subsubsection{Fast automated control and data acquisition}

We have tested each program alone, but we haven't yet run the two programs together due to a lack of suitable hardware.

\subsection{Moving Gas Outlets}

We have built the moving gas outlets and tested successfully their actuation. We plan to characterize the exchange of the gas around the sensor by laser induced fluorescence (LIF) [Lozano 1992]. We will tag one gas with a molecule like acetone that fluoresces upon UV illumination while the other gas streams remains dark.. 


\section{CONCLUSION}

Robust metallization techniques for depositing Pt sensing layer for $\mathrm{SiC}$ sensors were developed. The adhesion and stability of the Pt films was tested by cycling to $900 \mathrm{~K}$ and $1000 \mathrm{~K}$ using different heating techniques. The repeatability of the techniques we use to deposit the metal films was verified by XRD measurements which show that all our Pt layers, regardless of when and how they were deposited, are textured Pt (111) films. The reliability of the gold contacts to the Pt films was tested to $900 \mathrm{~K}$.

Hardware and software for fast sensor measurement has been built and tested at time scales from milliseconds to minutes. Manuals have been written to allow every user with previous experience in sensor measurements to use the developed programs. We plan to test the sensor measurement software in a model scale energy plant facility at the Morgantown, WV NETL site. The feedback for the sensor measurements has been optimized to a sub millisecond response to an instantaneous electrical change of the sensor. The new apparatus for fast sensor measurement is ready for a thorough characterization with visualized gas flows. 


\section{ACKNOWLEDGEMENTS}

We thank Mr. Nate Verhanovitz for programming our measurement software. We also thank Dr. Reza Loloee for the sputter deposition of the Pt films and the XRD measurements. 


\section{REFERENCES}

[Beadle 1985] W. E. Beadle, J. C. Tsai and R. D. Plummer, Quick Reference Manual for Si Integrated Circuit Technology, 6-34, Wiley, New York (1985).

[Cree] Cree Research Inc., Durham, NC 27703, USA.

[Filippov 1999] V. I. Filippov, A. A. Vasilev, A. A. Terentev, W. Moritz and U. Roth, "Sensor Based on a Pt/LaF3/SiO$/ 2 / S i C$ Structure for the detection of chlorofluorocarbons", Tech. Phys. 44, 1334-1339 (1999).

[Ghosh 2002] R. N. Ghosh, P. Tobias, S. Ejakov and B. Golding, "Interface States in High Temperature SiC Gas Sensing”, Proc. IEEE Sensors 2002, 2, 1120-1125, paper 6-4 (2002).

[Ghosh 2003] R. N. Ghosh, P. Tobias and B. Golding, "Influence of interface states on high temperature SiC sensors and electronics", in SiC - Material, Processing and Devices 2002, Mat. Res. Soc. Symp. Proc. 742, paper K7.5 (2003).

[Hunter 2000] G. W. Hunter, P. G. Neudeck, M. Gray, D. Androjna, L.-Y. Chien, R. W. Hoffman, Jr., C. C. Liu and Q. H. Wu, "SiC-based Gas Sensor Development', Mater. Sci. Forum 338-342, 1439-1422 (2000).

[Katsuta 1979] H. Katsuta ad R. B. McLellan, J. Phys. Chem. Solids, "Diffusivity, Permeability and Solubility of Hydrogen in Platinum”, 40, 697-699, (1979).

[Kim 2001] C. K. Kim, J. H. Lee, S. M. Choi, I. H. Noh, H. R. Kim, N. I. Cho, C. Hong and G. E. Jang, "Pd and Pt SiC Schottky Diodes for Detection of $\mathrm{H}_{2}$ and $\mathrm{CH}_{4}$ at High Temperature", Sensor. Actuat. B-Chem. 77, 455-462 (2001).

[Larsson 2002] O.Larsson, A. Göras, J. Nytomt, C. Carlsson, A. Lloyd Spetz, T. Artursson, M. Holmberg, I. Lundström, L.-G. Ekedahl, and P. Tobias, Estimation of air fuel ratio of individual cylinders in SI engines by means of MISiC sensor signals in a linear regression model, SAE2002, Detroit, USA, March 4-7, 2002, (2002-01-0847). [Lipkin 1996] L. A. Lipkin and J. W. Palmour, "Improved Oxidation Procedures for Reduced $\mathrm{SiO}_{2} / \mathrm{SiC}$ Defects", J. Electron. Mater., 25, 909-915, (1996).

[Lozano 1992] Lozano, Xip, and Hanson, Experiments in Fluids, 13, p. 369, (1992). [Lundstrom 1976] I. Lundström and T. DiStefano, "Influence of Hydrogen on $\mathrm{Pt}_{-\mathrm{SiO}}-\mathrm{Si}$ Structures”, Sol. St. Comm. 19, 871-875 (1976).

[Nakagomi 2001] S. Nakagomi, Y. Shindo, and Y. Kokubun, "Stability of electrical properties of high-temperature operated H-2 sensor based on Pt-I-SiC diode" Phys. Stat.

Solidi A 185, 33-38 (2001).

[Samman 2000] A. Samman, S. Gebremariam S, L. Rimai L, X. Zhang, J. Hangas and G. W. Auner, "Silicon-carbide MOS Capacitors with Laser-ablated Pt Gate as Combustible Gas Sensors", Sensor. Actuat. B-Chem. 63, 91-102 (2000).

[Serina 2001] F. Serina, K. Y. S. Ng, C. Huang, G. W. Auner, L. Rimai and R. Naik, "Pd/AlN/SiC Thin-film Devices for Selective Hydrogen Sensing", Appl. Phys. Lett. 79, 3350-3352 (2001). 
[Spetz 2001] A. Lloyd Spetz, L. Unéus, H. Svennningstorp, P. Tobias, L. G. Ekedahl, O. Larsson, A. Göras, S. Savage, C. Harris, P. Mårtensson, R. Wigren, P. Salomonsson, B. Häggendahl, P. Ljung, M. Mattsson and I. Lundström, "SiC Based Field Effect Gas Sensors for Industrial Applications", Phys. Stat. Solidi A 185, 15-25, (2001).

[Tobias 1999] P. Tobias, P. Martensson A. Goras, I. Lundström, A. Lloyd Spetz, "Moving gas outlets for the evaluation of fast gas sensors", Sens. Actuat. B. 58, 389-393, (1999).

[Tobias 2003A] P. Tobias, B. Golding and R. N. Ghosh, "Interface states in hightemperature gas sensors based on silicon carbide", invited issue of IEEE Sensors Jour. 2 , 543-547, (2003).

no reference use of [Tobias 2003B] P. Tobias, G. Golding and R. N. Ghosh, "Sensing Mechanisms of high temperature silicon carbide field-effect devices", Transducer 2003, paper 2E4.P (2003).

\section{BIBLIOGRAPHY}

None

\section{LIST OF ACRONYMS AND ABBREVIATIONS}

$\mathrm{SiC}$ - silicon carbide

$\mathrm{SiO}_{2}$ - silicon dioxide

MISiC - metal insulator silicon carbide (device)

Quasi-static - calculated C-V from the charge flowing onto a sensor at each voltage step

TPD - temperater programmed desorption

QMS - quadrupole mass spectrometer

UHV - ultra high vacuum 